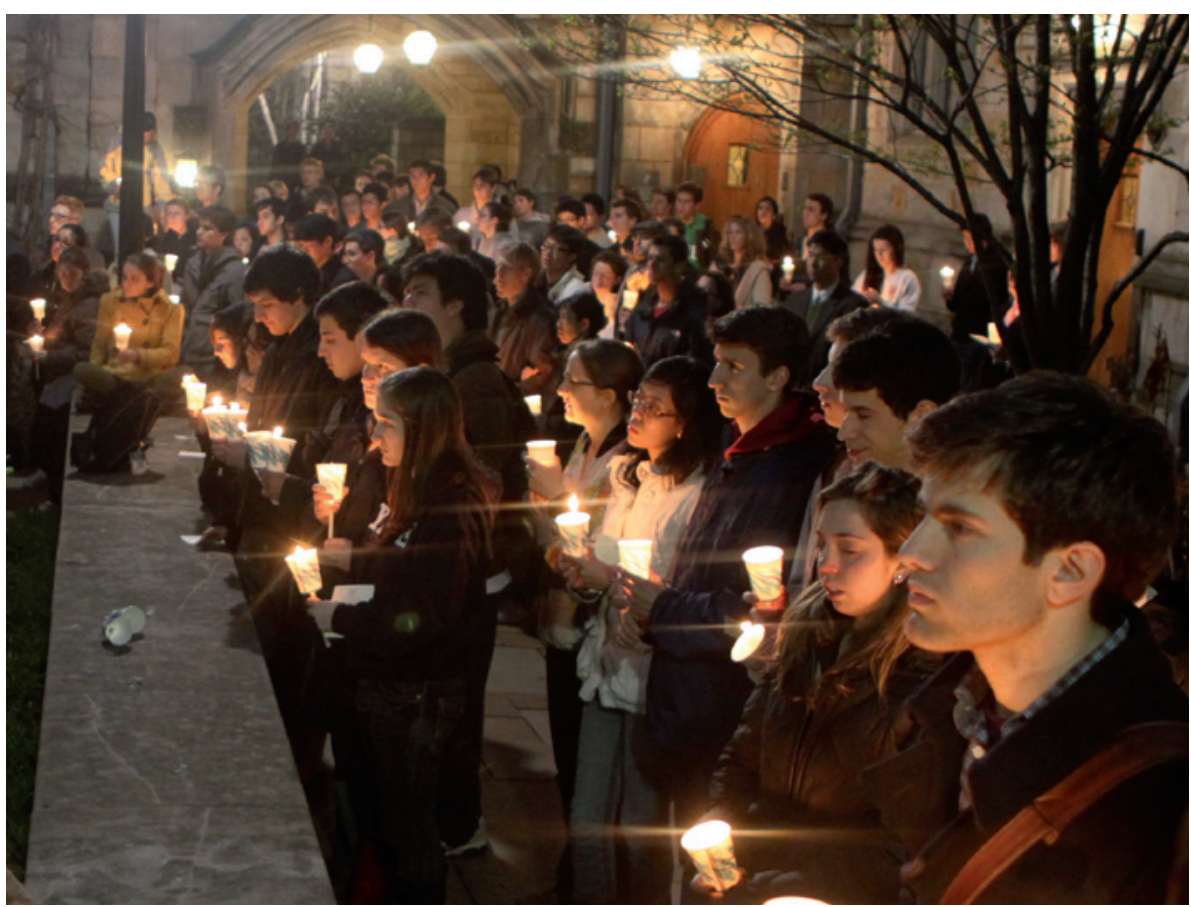

Fellow students hold a vigil for Yale undergraduate Michele Dufault.

HIGHER EDUCATION

\title{
A death in the lab
}

\section{Fatality adds further momentum to calls for a shake-up in academic safety culture.}

\section{BY RICHARD VAN NOORDEN}

$\mathrm{I}$ the early hours of 13 April, undergraduate students working at Yale University's Sterling Chemistry Laboratory made a shocking discovery. There in the lab's machine shop was the dead body of 22-year-old undergraduate student Michele Dufault, her hair tangled in a lathe. She had apparently died of asphyxiation in an accident described by Richard Levin, president of Yale in New Haven, Connecticut, as a "true tragedy".

Within days, federal health and safety officials had started to investigate. Details are scarce, but it is already clear that Dufault was not inexperienced with the equipment; she had taken a training course and had used the lathe safely many times before, according to fellow physics student Joe O'Rourke. She was, however, working late at night and probably alone (a speculation that Yale would not confirm) - circumstances that were not unusual at the machine shop, says O’Rourke.

Around the United States, laboratory directors and safety officers immediately checked their own policies on working practices in machine shops. But the accident has also heightened wider concerns about the ever-present tension between research freedom and safe working conditions in academia. And it underscores the slow pace of change since another high-profile laboratory fatality led to similar soul-searching less than three years ago.

In late 2008, 23-year-old research assistant Sheharbano Sangji sustained horrific burns in a lab fire at the University of California, Los Angeles (UCLA), and died of her injuries 18 days later. Sangji's death - in very different circumstances from Dufault's - resulted in federal fines for the university and a rapid toughening of safety policies there. On 30 March, UCLA unveiled its latest safety initiative: a new Center for Laboratory Safety, which is billed as the first in the United States to measure the effectiveness of safety policies and develop ways to improve scientists' approach to safety. More widely, Sangji's accident acted as a lightning rod for demands to improve standards across the United States.

Yet for all this attention, health and safety experts say that they have not seen a significant shift in the behaviour of bench scientists or the attitudes of lab heads, who are in the best position to improve safety culture. "It's very difficult to change principal investigators' attitudes," says
James Gibson, UCLA's director of environmental health and safety. All too often, researchers in laboratories around the country still work alone, and without proper supervision or protection. "In many cases, academic freedom is more important than safety," says Jim Kaufman, president of the Laboratory Safety Institute in Natick, Massachusetts.

\section{CHEMICAL FOCUS}

Although such concerns apply across academia, accidents in chemistry laboratories have drawn the most scrutiny in recent years. A year after Sangii's death, Preston Brown, a graduate student in chemistry at Texas Tech University in Lubbock, lost three fingers of his left hand during a dangerous experiment. Brown was grinding up chunks of nickel hydrazine perchlorate - using a hundred times the recommended amount - when it detonated.

Unusually, the US Chemical Safety Board (CSB) - a body that usually investigates large industrial accidents such as refinery explosions - stepped in. For the first time ever, it said it would review academic laboratory safety. At an August 2010 meeting of the American Chemical Society in Boston, Massachusetts, CSB chairman Rafael Moure-Eraso said that the board had gathered media reports of around 120 university chemistry laboratory accidents since 2001, and concluded that "safety practices at US universities leave a lot to be desired".

Chemistry labs have been a particular focus of concern because the most dangerous procedures in other sciences tend to have more detailed safety protocols, says Peter Reinhardt, head of environmental health and safety at Yale University. "Using radioactive materials or biological materials is much more stringently regulated," he told Nature (speaking before Dufault's accident). "The big gap is hazardous chemicals in laboratories."

Rick Danheiser, an organic chemist at the Massachusetts Institute of Technology in Cambridge who chairs the chemistry department's health and safety committee, agrees that some labs' safety standards are too lax. But "there are chemistry departments with very strong safety programmes, and there's a whole range of laboratories in between", he says.

Neal Langerman, who runs the consulting company Advanced Chemical Safety, based in San Diego, California, is more strident about the extent of the problem. "I have come to the conclusion that most academic laboratories are unsafe venues for work or study," he wrote in a 2009 opinion column in the Journal of Chemical Health and Safety. He now says that, despite the recent accidents, he has not noticed a significant change in chemists' attitude to safety.

US scientists are undeniably much safer today than before swathes of occupational health legislation arrived in the 1970s, along with a new watchdog agency, the federal Occupational Safety and Health Administration (OSHA). Further improvements came in 
1991, when OSHA stipulated that each chemistry lab should prepare a 'chemical hygiene plan' - effectively a handbook detailing safety protocols and emergency procedures - although these requirements are rarely enforced by inspections.

The US Bureau of Labor Statistics says that the rate of recordable incidents in scientific research and development services has fallen from 2.1 per 100 full-time employees in 2003 to 1.2 in 2009 . But the government does not track major accidents or near misses specifically in academic laboratories. "Anecdotally, most people agree that university labs have more frequent and more frequently serious accidents than industry," says Dorothy Zolandz, director of the National Academies Board on Chemical Sciences and Technology.

Researchers often point out that industry is in a better position than academia to keep safety standards high because it has a clear hierarchy of power, fewer inexperienced students, and accountability to management. One of the clearest difference lies in lone working: surveys by the American Chemical Society last year suggest that $70.5 \%$ of faculty and $52.1 \%$ of graduate students often or occasionally work alone in laboratories, something that is forbidden in industry.

Safety officers and experienced chemists say that good laboratory safety relies on far more than regular inspections. What's key, says Tom Welton of Imperial College London, is that the group's research leader accepts unequivocal responsibility for the safety of everyone doing science in the laboratory, building a culture where researchers instinctively have safety foremost in their minds.

Evidence presented at a US National Research Council meeting on laboratory safety in November 2010 backs up Welton's point. Ron Zanoni, manager of occupational safety at international chemicals giant Arkema, based in Colombes, France, showed a 2004 survey that found case injury rates ranging from 7.8 to 0.8 per year at Arkema's various US sites. The differences correlated well with working relationships and top-down leadership engagement at different sites, Zanoni says. Improving safety leadership at labs with poor records had reduced injury rates by 2007 .

As UCLA has found, it can be hard to change researchers' mindsets, even after a death on campus. Over the past two years, the university has ramped up laboratory safety regulations,
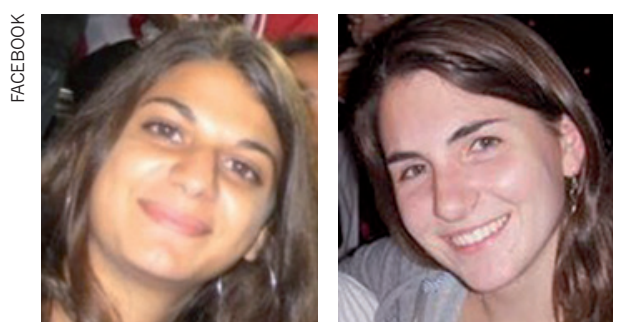

Sheharbano Sangji (left) and Michele Dufault.

training and inspections. But Nancy Wayne, a physiology professor on the board of the new laboratory safety centre, says researchers at UCLA do not always appreciate the tougher regime, sometimes seeing environmental inspectors as 'police', rather than partners in improving standards. "Changing the culture is really going to be a long-term challenge," says Gibson. Some professors, he says, have even questioned the need for flame-resistant lab coats - a bitter irony given the circumstances of Sangji's accident.

She was using a syringe to draw reactive $t$-butyl lithium from a bottle when it burst into flames, setting her clothes alight. She was not wearing a lab coat. Since then, the California Division of Occupational Safety and Health has agreed fines with UCLA of around US $\$ 70,000$ for safety violations. Sangji's supervisor, Patrick Harran, declined Nature's request for an interview. The Los Angeles district attorney is still reviewing Sangii's case, and has not yet decided whether to press criminal charges against either Harran or UCLA. If this resulted in a conviction, "the rules

"Changing

the culture is really going to be along-term challenge." change completely right then and there", says Langerman. "All of a sudden, if you hurt somebodybadly, you may face felony charges."

In the United Kingdom, the threat of legal action has proved to be a powerful incentive for change. Around 25 years ago, an explosion in a chemistry laboratory at Sussex University in Brighton shot a piece of metal into a student's abdomen. The student eventually recovered, but the government's Health and Safety Executive prosecuted Sussex University for negligence. The episode had a profound effect on safety standards in Britain, says Welton. Today, British researchers are required to write down risk assessments before every experiment, something that is not required in the United States.

"I think that it will take a professor being punished, perhaps unfairly, to really engender change on the part of academia overall," says chemical-safety blogger Chemjobber, an industrial synthetic organic chemist in the United States. But funding agencies could also play a part. The CSB, for example, is considering recommending that grant applications should contain specific safety-training requirements.

"I think in the long run, the CSB recommendations, a possible new OSHA lab standard, and input from the American Chemical Society will result in a modification of the regulatory climate," says Langerman. But scientists should not wait for those changes before taking the initiative on safety, he adds.

"Members of the academic community have unique freedoms that are denied to industry," he says. "They then have a unique responsibility to behave in a manner that supports the freedom they are given." — SEE EDITORIAL P.259 